\title{
ABUNDANCE OF BOTTLENOSE DOLPHINS (Tursiops truncatus) IN ESTUARINE AND NEAR-SHORE WATERS OF NORTH CAROLINA, USA
}

\author{
KIM W. URIAN*, DANIELLE M. WAPLES, RENY B. TYSON, LYNNE E. W. HODGE, \\ AND ANDREW J. READ \\ Nicholas School of the Environment \\ Duke University \\ 135 Duke Marine Lab Road \\ Beaufort NC 28516 USA \\ *E-mail:kim.urian@gmail.com
}

\begin{abstract}
A capture-recapture survey of bottlenose dolphins (Tursiops truncatus) was conducted in the sounds, estuaries and near-shore waters of North Carolina during July 2006, using photographic identification techniques; 291 dolphins were identified from distinctive nicks and notches on their dorsal fins. The results of our photographic analyses were applied to several capture-recapture models. The best estimate of the number of bottlenose dolphins present in estuarine waters of North Carolina during July 2006 was 813 with a 95\% Confidence Interval of 483-1,142. Previously in July 2000, 1,033 (95\% CI: 8601,266) dolphins were estimated to be present in the estuaries of North Carolina. When the analysis from the 2006 surveys was expanded to include adjacent coastal waters, then the estimate of abundance increased to 1,138 . Therefore, the abundance of dolphins in this area remained relatively stable between the two studies. Most dolphins were found in the northern part of the study area and there was very little exchange between the northern and southern areas of the state. The recapture data was also used to identify a spatial boundary between two putative management units that may be useful for future stock delineations. Additionally, an unexpected potential bias was introduced with the transition from slide film to digital media in the evaluation of the distinctiveness scoring.
\end{abstract}

Key Words: Bottlenose Dolphins; Tursiops truncatus; Capture-Recapture; Photo-Identification; Abundance.

\section{INTRODUCTION}

The population structure of bottlenose dolphins (Tursiops truncatus) in coastal and estuarine waters of the Atlantic coast of the United States is characterized by a complex mixture of resident and migratory animals, with some degree of seasonal mixing (Waring et al. 2011). A photographic capture-recapture survey was conducted in the estuaries of North Carolina in July 2000 to estimate the abundance of bottlenose dolphins and the resulting estimate was 1,033 dolphins (95\% CI 860-1,266, CV = 0.099) (Read et al. 2003). This was the first estimate of abundance for this species in the inshore waters of North Carolina; the estimate has been used in the formal NOAA Fisheries stock assessment process (Waring et al. 2007). Since those surveys were conducted our understanding of the population structure of bottlenose dolphins in this region has improved considerably; four management units have been designated in North Carolina alone, including two resident estuarine and two migratory coastal stocks (Waring et al. 2011). The two resident stocks occur primarily in estuarine waters, with some movement into near-shore coastal waters; these stocks have been designated as the Northern North Carolina (NNCES) and Southern North Carolina (SNCES)
Estuarine Stocks, respectively, by NOAA Fisheries (Waring et al. 2011). The ranges of these two management units in coastal waters overlap with those of the Northern and Southern Migratory management units during certain seasons.

To estimate the abundance of bottlenose dolphins a capture-recapture approach was employed, a technique used widely in ecological studies to estimate the number of marked individuals in a population (Otis et al. 1978). Natural marks on the dorsal fins of dolphins were documented using photographs to identify individual animals (Hammond et al. 1990; Williams et al. 1993; Wilson et al. 1999; Read et al. 2003). This method made several assumptions about the behavior of the animals, the efficiency of the sampling and our ability to recognize animals on recapture. Sampling and identification procedures were designed to minimize the impact of violating these assumptions.

Most of the methods used during our 2000 survey were duplicated in 2006 (Read et al. 2003). The 2006 effort differed from the previous work in only two important aspects; in 2006 adjacent coastal ocean waters were included, so that we could provide more comprehensive estimates of abundance for the stocks of bottlenose dolphins in the state. Likewise, digital 
photography was used in the 2006 survey, rather than photographic transparencies (e.g., $35 \mathrm{~mm}$ slide film).

Herein a new estimate of abundance was derived from effort in 2006 that included coastal waters up to $1 \mathrm{~km}$ from shore and was structured to reflect the existence of the two estuarine management units. Another objective of this study was to determine whether abundance had changed during the six years since the first survey, because dolphins from both management units are taken as by-catch in coastal gill net fisheries (Waring et al. 2011).

\section{METHODS}

Field Effort

Two photographic surveys were conducted for bottlenose dolphins throughout the inshore and coastal waters of North Carolina during July 2006. The surveys were conducted a week apart, to minimize the possibility of dispersal, mortality or births between the two sampling periods. Three vessels were used simultaneously in each survey: one in the southern portion of the state (Southport, Cape Fear River, New River, Bogue Sound), a second in the central portion (Newport River, Core Sound, Neuse River, Pamlico River and southern Pamlico Sound), and a third in the northern portion (northern Pamlico Sound and Roanoke Sound); hereafter referred to as Southern, Central and Northern surveys. The surveys were conducted from outboardpowered, center-console research boats operated by the Duke University Marine Laboratory and the University of North Carolina Wilmington.

Researchers on each boat included a skipper, one or two photographers and a data recorder. Survey routes were recorded continuously with a GPS, and any changes in sighting conditions during the course of the survey were noted. Optimal survey conditions were required to obtain good quality dorsal fin images (Beaufort Sea State 2 or less). At each encounter with dolphins the position (using a GPS unit), water depth and the approximate number of dolphins were recorded. Photographs were taken of the dorsal fin of each dolphin using Nikon digital cameras equipped with 300$\mathrm{mm}$ zoom lenses. Every attempt was made to photograph each dolphin in all encounters.

\section{Photo-Identification}

The software program ACDSee PhotoManager 8 was used to organize digital images of dorsal fins. Each digital image was identified with the date and encounter number. Prior to photo-identification, images of dolphin dorsal fins were graded for photographic quality (PQ) (Urian et al. 1999; see Appendix 1-revised from Read et al. 2003). The photographic quality score was based on a weighted scale that incorporated: focus and clarity; contrast; angle of the fin to the photographer; and visibility of the fin in the frame. Any image at an oblique angle or that did not show the entire trailing edge of the dorsal fin from the tip to the posterior insertion was excluded from further analysis. Excellent quality images (PQ1) received scores from 6-9; good quality images (PQ2) ranged from 10-12; and poor quality images (PQ3) scored 13 and higher.

The distinctiveness (D) of features (predominantly nicks on the trailing edge) on each dolphin's dorsal fin was also scored (see Appendix 1; Read et al. 2003). Dolphins with the most distinctive features, evident in even a poor quality photograph, were scored D1; those with at least two distinguishing features or one major feature were scored D2. Animals with few or no distinctive characteristics received a score of D3. Only animals that were scored with D1 and D2 were considered "marked." One researcher evaluated image quality and a second researcher graded distinctiveness to minimize the potential interplay between image quality and distinctiveness. Images that included multiple marked dolphins were cropped to include only a single dolphin in each frame; most images were cropped to show the entire leading and trailing edges of the fin, and all fin features.

Capture-recapture analysis was restricted to the highest quality images (PQ1) of dolphins with the most distinctive features (D1) to maximize the probability of recognizing marked individuals - those with large nicks and notches, multiple notches or leading edge features. This minimized subjectivity in the matching process and reduced the chance of making incorrect identifications or missing matches altogether (Hammond 1986; Hammond 1990; Read et al. 2003; Friday et al. 2008), although at the expense of some precision. Images of individual dolphins were sorted based on the location of the most prominent feature on their fin and each individual was given an identification number and its image placed in a catalog folder. Each distinctive dolphin was compared to every other marked individual before adding it to the catalog; a second researcher verified every potential match of an individual dolphin from one encounter to another. Data from left and right side photographs were pooled as fin edge features are equally visible from either side. All images were combined into a single sample from each survey; thus, the images taken from all three boats were combined into one sample (Read et al. 2003).

\section{Estimation of Abundance}

Established capture-recapture models that assumed demographic closure between sampling occasions were 
applied to the results of the photographic analyses of marked individuals. The duration of the sampling (three weeks) was sufficiently short so that we could safely assume the population was closed to demographic changes (births and deaths) during this period (Otis et al. 1978; Wells and Scott 1999; Read et al. 2003). Thus, closed population models $\left(\mathrm{M}_{(\mathrm{t})}\right.$ (Darroch 1958) and $\mathrm{M}_{(\mathrm{th})}$ (Chao et al. 1992)) were chosen to derive estimates of abundance for this period. The program CAPTURE (Otis et al. 1978; White et al. 1982) was used and each survey day was considered a sampling occasion (Read et al. 2003).

Initial estimates pertained only to the population of marked animals, so to account for unmarked dolphins in the images taken, these estimates were divided by theta (the proportion of images with marked animals in the sample). Theta was calculated by counting the proportion of marked (D1) to unmarked (D2 and D3) animals in all PQ1 images (Williams et al. 1993). Variances were calculated using the delta method (Wilson et al. 1999). The final confidence intervals assume the same error distribution as the marked population estimate.

Conventional mark-recapture models operate under assumptions about the nature of the study population and the way it is sampled. Violations of these assumptions can lead to biased estimates, so it is important that they are explored and validated, or that appropriate models are selected to take account of them (Begon 1983). As in Read et al. 2003 our methods were designed to minimize the potential for violation of these assumptions. Because of the brevity of this study, in comparison to the longevity and low reproductive rates of bottlenose dolphins, the population was assumed to be demographically closed and the potential bias of capture heterogeneity was addressed by applying mark-recapture models designed specifically to address this issue (see Read et al. 2003).

\section{RESULTS}

\section{Field Effort}

Photo-identification surveys were conducted in July 2006 throughout the inshore and coastal waters of North Carolina during two, week-long blocks separated by seven days (July 6-11 and July 19-21; 23-26) (Fig. 1). Field hours, numbers of encounters and numbers of photographs taken were comparable in both the 2000 and 2006 studies (Table 1). The present survey effort focused on shallow water habitats along shorelines, as previous experience and information from other researchers and local watermen indicated that few dolphins are present in other areas.

\section{Photo-Identification}

We obtained and examined 10,956 photographs. Of these, 3,868 images (35\%) received excellent photographic quality scores (PQ1) and thus met the criteria for analysis; 781 were considered good quality (PQ2). From these images we identified forty-nine highly distinctive (D1) dolphins; 242 individuals were assigned a score of D2. Seventy-six of D1 and D2 dolphins were photographed more than once during the surveys and four were photographed on four separate days.

The movements of individual dolphins during the 2006 surveys were similar to the patterns we observed in 2000 and consistent with our understanding of bottlenose dolphin population structure in this region. To increase re-sighting rates, all D1 and D2 dolphins identified from PQ1 and PQ2 images (excellent and good images only), ( $\mathrm{n}=291$ individuals) were examined. No matches were made between dolphins photographed by the northern and southern survey teams, but 15 dolphins were matched between the northern and central survey teams in the range of the NNCES management unit. Only two dolphins were matched between the central and southern teams, near the boundary of the NNCES and SNCES management units (Waring et al. 2011). Furthermore, as expected, dolphins moved between estuarine and coastal waters; 232 dolphins were photographed only in estuaries, 47 dolphins were observed only in coastal waters and 12 dolphins were photographed in both estuarine and coastal waters. Three hundred and six dolphins were identified in the July 2000 survey and sixty-seven (22\%) of these individuals were re-sighted in July 2006.

Group sizes of dolphins in the northern part of the study area, in the range of the NNCES, were significantly larger than those in the southern area, in the range of the SNCES $(21.4 \pm 26.7 \mathrm{SD}$ and $9.8 \pm 10.5 \mathrm{SD}$ respectively, 2-sample $t$ test, $\mathrm{p}=0.026$ ) (Table 2), similar to the previous findings (Read et al. 2003). There was no consistent pattern in variation of group size in estuarine versus coastal waters (2-sample $t$ test, $\mathrm{p}=$ 0.822), (Table 3).

\section{Estimation of Abundance}

Estimates of abundance were similar across the various models explored. It is clear from other research, including our previous study, that heterogeneity of capture probabilities with this species is common and should be included in any capture-recapture model (e.g., Wilson et al. 1999). Of the models that incorporated heterogeneity, the $\mathrm{M}_{(\mathrm{t})}$ model allowed capture probability of individuals to vary over time (Darroch 1958), and was, therefore, the model of choice; this was also the model that was applied to the 2000 capture-recapture data. The Darroch model had the added benefit of generating the smallest variance and thus was also the most precise estimate. Theta (the proportion of marked animals in the population) was estimated to be 0.08 for this dataset and was used to 


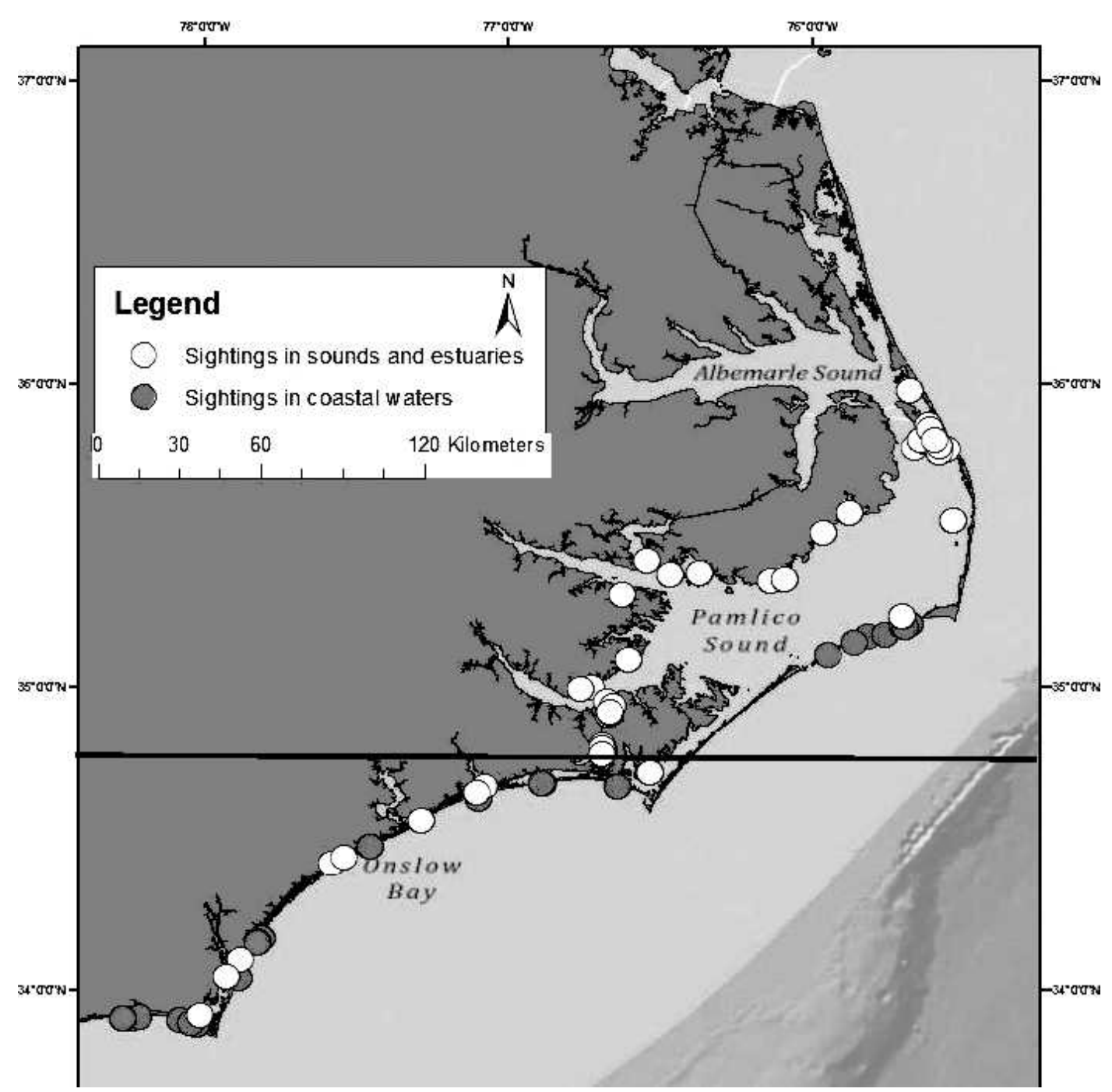

FIG. 1. Location of encounters with dolphins in the estuaries and coastal waters of North Carolina up to $1 \mathrm{~km}$ from shore. Horizontal black line $\left(34^{\circ} 46^{\prime} \mathrm{N}\right)$ demarcates northern and southern areas for which abundance was estimated separately.

scale the estimate to a total population size (Table 4). Application of this model to the data set yielded an estimate of 813 dolphins (Table 5) in North Carolina estuaries during July 2006.

Expanding the analysis to include the effort in the adjacent coastal waters, the estimate of abundance increased to 1,138 (Table 5), again using the $\mathrm{M}_{(\mathrm{t})}$ model, which again yielded the estimate with the lowest

Table 1. Comparison of survey effort between July 2000 (Read et al. 2003) and July 2006. Note: Effort in 2006 included surveys in coastal waters up to $1 \mathrm{~km}$ from shore.

\begin{tabular}{lcc}
\hline & 2000 & 2006 \\
\hline Time period & $2-25$ July & $6-26$ July \\
Survey days (d) & 12 & 13 \\
Field hours (h) & 252 & 236 \\
Number of encounters & 66 & 92 \\
Number of photographs & 7,682 & 10,956 \\
\hline
\end{tabular}

variance. Applying the Chapman's modification of a Lincoln-Peterson two-sample model (Chapman 1951) to the 2006 data set (including both coastal and estuarine waters) by considering the two week-long surveys as separate sampling occasions generated an identical point estimate of abundance of 1,138 dolphins (95\% CI $641-1,634, \mathrm{CV}=0.22$ ).

To determine the spatial boundary between the northern and southern management units in an objective

Table 2. Estimates of group size for 2006 photographic capturerecapture surveys.

\begin{tabular}{lccc}
\hline & Northern & Central & Southern \\
\hline Number of sightings & 33 & 28 & 31 \\
Mean & 21.4 & 17.9 & 9.8 \\
SD & 26.7 & 20.5 & 10.5 \\
Range & $1-120$ & $1-75$ & $1-47$ \\
\hline
\end{tabular}


Table 3. Group size estimates for combined coastal and estuary sightings of bottlenose dolphins.

\begin{tabular}{lcc}
\hline & Coastal & Estuary \\
\hline Number of sightings & 27 & 65 \\
Mean & 15.7 & 16.7 \\
SD & 16.3 & 22.6 \\
Range & $1-75$ & $1-120$ \\
\hline
\end{tabular}

manner, sighting locations of the dolphins from the larger dataset of D1 and D2 individuals in PQ1 and PQ2 images were plotted in $\operatorname{ArcMap}^{\circledR} 10$, using methods described in Tyson et al. (2011). A potential boundary "line" was placed every $1,000 \mathrm{~m}$ between the minimum and maximum latitudinal values of the survey region $(\mathrm{n}=$ 227 lines) and the number of individuals seen on both sides of each line was recorded (custom written code; $\mathrm{R}$ Core Development Team 2008). If any particular line approximated the true latitudinal boundary, few animals would be seen on both sides of that line. The boundary line $\left(34^{\circ} 46^{\prime} \mathrm{N}\right.$; Fig. 1) that resulted from this analysis is consistent with the demarcation line used for estimating abundance for the northern and southern parts of the study area in 2000. Separate abundance estimates were generated for the northern and southern parts of the study area using the boundary line described above to subdivide the dataset. The restricted dataset (PQ1 and D1) of combined coastal and estuarine sightings was used to estimate abundance for the northern and southern areas with the $\mathbf{M}_{(\mathrm{t})}$ model (Darroch 1958). Nine hundred and fifty individuals were estimated in the northern part of the study area and 188 dolphins in the southern part (Table 5). These estimates are comparable to the results from 2000 (northern $=919$ individuals and southern $=$ 141), although the 2000 estimates did not include coastal waters (Table 5).

\section{DISCUSSION}

The best estimate of the number of bottlenose dolphins present in the sounds and estuaries of North Carolina during July 2006 was 813 with a 95\% Confidence Interval of 483-1,142. The previous estimate in July 2000 was 1,033 (95\% CI: 860-1,266) dolphins present in the estuaries of North Carolina (Read et al. 2003). The point estimate of

Table 4. Comparison of values of theta (the proportion of marked animals in a population, $\mathrm{n}=$ number of images) from July 2000 and July 2006.

\begin{tabular}{ccllc}
\hline & & \multicolumn{1}{c}{2000} & & 2006 \\
\cline { 3 - 3 } \cline { 5 - 5 } Distinctiveness & Image quality & \multicolumn{1}{c}{ Theta $(\mathrm{n})$} & & Theta $(\mathrm{n})$ \\
\hline D1 & PQ 6-9 & $0.18(743)$ & & $0.08(3,868)$ \\
D1+D2 & PQ 6-9 & $0.68(743)$ & & $0.55(3,868)$ \\
D1+D2 & PQ 6-12 & $0.39(3,457)$ & & $0.45(4,649)$ \\
D2 & PQ 6-12 & $0.36(3,457)$ & & $0.38(4,649)$ \\
\hline
\end{tabular}

Table 5. Comparison of estimates of abundance (N), with associated confidence intervals $(\mathrm{CI})$ and coefficients of variance $(\mathrm{CV})$, between July 2000 (Read et al. 2003) and July 2006. The $\mathbf{M}_{(\mathrm{t})}$ Darroch model was applied to all estimates. Note: Estimates in 2000 were derived from D1 and D2 individuals in PQ1 and PQ2 images, whereas in 2006 we restricted our dataset to D1 individuals in PQ1 images. Effort in 2006 included surveys in coastal waters up to $1 \mathrm{~km}$ from shore.

\begin{tabular}{lcc}
\hline \multicolumn{1}{c}{2000} & 2006 \\
\hline Estuaries & & \\
$\mathrm{N}$ & 1,033 & 813 \\
$95 \% \mathrm{CI}$ & $860-1,266$ & $483-1,142$ \\
$\mathrm{CV}$ & 0.10 & 0.21 \\
Estuaries and coastal waters & & \\
$\mathrm{N}$ & $\mathrm{N} / \mathrm{A}$ & 1,138 \\
$95 \% \mathrm{CI}$ & $\mathrm{N} / \mathrm{A}$ & $735-1,540$ \\
$\mathrm{CV}$ & $\mathrm{N} / \mathrm{A}$ & 0.18 \\
Northern & & \\
$\mathrm{N}$ & 919 & 950 \\
$95 \% \mathrm{CI}$ & $730-1,190$ & $516-1,384$ \\
$\mathrm{CV}$ & 0.13 & 0.23 \\
Southern & & 188 \\
$\mathrm{~N}$ & 141 & $118-257$ \\
$95 \% \mathrm{CI}$ & $112-200$ & 0.19 \\
$\mathrm{CV}$ & 0.15 & \\
\hline
\end{tabular}

abundance for dolphins in July 2006 is lower than the point estimate for July 2000 (813 vs. 1,033 dolphins), but the confidence intervals overlapped broadly, indicating that the two estimates are not statistically different. Expanding the analysis to include adjacent coastal waters from the 2006 surveys, the estimate of abundance increased to 1,138 (Table 5). Applying the Chapman's modification of a Lincoln-Peterson two-sample model (Chapman 1951) to the 2006 data set (including both coastal and estuarine waters) interestingly, yielded an identical point estimate of abundance of 1,138 dolphins (95\% CI 641-1,634, CV $=0.22$ ). Therefore, the abundance of dolphins in this area remained relatively stable in the time period between these two studies.

We believe that an estimate derived from both coastal and estuarine waters is preferable because we know that some dolphins move between estuarine and coastal habitats. For example, 12 of 291 dolphins were photographed in both estuarine and coastal waters during our two-week study. Direct comparisons between this estimate and results of the 2000 study are not possible because the coastal waters were not surveyed in the earlier study.

A novel potential bias was found during our analysis in the evaluation of distinctiveness; we found a large discrepancy between estimates of abundance generated from datasets using the D1 versus the D1 and D2 individuals combined. The value of theta for D2 dolphins was lower in $2000(0.36)$ than in $2006(0.46)$, suggesting that a larger number of D2 individuals were included in the current analysis (Table 4). This is most 
likely a result of the transition from slide film to digital images between the two study periods. Many dorsal fin images were excluded in the 2000 study because of the difficulty in identifying subtle features in slide film. One of the scores used for evaluating image quality is the "proportion of the fin in the frame." With digital images it is possible to zoom into and crop an image, so that less obvious features are visible, especially when matching over short time periods. Therefore, more fins from 2006 were scored as D2 (rather than D3) because features not readily apparent in the slide film could be identified in digital images. Unfortunately these subtle marks may not have been visible in lower quality images, and thus those individuals may not have been re-captured reliably. To address this potential bias, the analysis was restricted to D1 dolphins, which had the consequence of inflating estimates of variance due to the relatively small sample of very well marked animals. This issue clearly warrants further investigation, but it was prudent to restrict the input data to animals with D1 type marks when calculating the final abundance estimates. This restricted the sample of marked animals considerably, resulting in larger confidence intervals, but it avoided the inherent bias associated with unrecognized animals on recapture. Other researchers should address the potential effects of variation in distinctiveness and photographic quality and the interplay between these two parameters in estimates of the abundance of small cetaceans.

The movements of individual dolphins between week one and two during these surveys were similar to the patterns observed in July 2000. No exchange was observed between the northern and southern portions of the state, but there was considerable movement within Pamlico Sound. Applying an objective method to identify a spatial boundary between the northern and southern areas of the state resulted in a demarcation line that was identical to the one identified in the 2000 study. This spatial boundary may provide a useful delineation of the NNCES and SNCES management units. In addition, the sighting patterns observed indicated that at least some dolphins exhibit long-term residency in $\mathrm{NC}$ waters; we re-sighted $22 \%$ of the dolphins from the 2000 surveys in 2006.

NOAA Fisheries is continually reassessing the designation of bottlenose dolphin stocks in North Carolina. The current structure includes four stocks of dolphins: the Northern North Carolina Estuarine Stock; the Southern North Carolina Estuarine Stock; the Northern Migratory Stock; and the Southern Migratory Stock (Waring et al. 2011). The results of our study strongly support the existence of two estuarine stocks in North Carolina during the summer: the Northern North Carolina Estuarine Stock that ranges throughout Pamlico Sound, but is rarely seen south of the New River; and the Southern North Carolina Estuarine Stock that ranges south to the South Carolina/North Carolina border and north to Bogue Sound and Cape Lookout.

As previously reported, these methods are highly useful for estimating the abundance of bottlenose dolphins in the estuarine and coastal waters of NC. Similar studies could utilize similar methods to estimate the population size of other resident stocks of bottlenose dolphins along the eastern seaboard of the United States.

Acknowledgments: We thank Dee Allen, Paula Gillikin, Lucie Hazen, Bob Jones, Erin LaBrecque, Jeff Moore, Lesley Thorne, Leigh Torres and Peggy Sloan for conducting surveys. Rich Mallon-Day and Jessica Weiss helped us to locate dolphins in Roanoke Sound. AnnaMarie Laura graded images, organized datasets and entered data. Ben Wilson provided helpful analytical advice. Corrie Curtice conducted the analysis of the population boundary. We thank Bill Foster, Doug Champion, Susan Suggs, Captain Gerry Compeau of the Center for Marine Science Research of UNC Wilmington and the Duke University Marine Laboratory for logistical assistance. No experimentation was conducted on animals during the conduct of this research. This work was funded by the North Carolina Sea Grant's Fishery Resource Grant Program. Surveys were conducted under U.S. National Marine Fisheries Service General Authorization Number 808-1798.

\section{LITERATURE CITED}

BEGON, M. 1983. Abuses of mathematical techniques in ecology: applications of Jolly's capture-recapture method. Oikos 40:55-158.

CHAO, A., S. M. LEE, AND S. L. JENG. 1992. Estimating population size for capture-recapture data when capture probabilities vary by time and individual animal. Biometrics 48:201-216.

CHAPMAN, D. G. 1951. Some properties of the hypergeometric distribution with application to zoological sample censuses. Univ. of California Publ. Statistics 1:131-160.

DARROCH, J. N. 1958. The multiple recapture census: I. estimation of a closed population. Biometrika 45:343-359.

FRIDAY, N., T. D. SMITH, P. T. STEVICK, J. ALLEN, AND T. FERNALD. 2008. Balancing bias and precision in capturerecapture estimates of abundance. Mar. Mammal Sci. 24:253-275.

HAMMOND, P. S. 1986. Estimating the size of naturally marked whale populations using capture-recapture techniques. Reports of the International Whaling Commi. Spec. Issue 16:253-282.

HAMMOND, P. S. 1990. Capturing whales on film - estimating cetacean population parameters from individual recognition data. Mammal Rev. 20:17-22.

HAMMOND, P. S., S. A. MIZROCH, AND G. F. DONOVAN, eds. 1990. Individual recognition of cetaceans: use of photo-identification and other techniques to estimate population parameters. Reports of the International Whaling Commi. Spec. Issue 12. 440 p.

OTIS, D. L., K. P. BURNHAM, G. C. White, AND D. R. ANDERSON. 1978. Statistical inference from capture data on closed animal populations. Wildlife Monogr. 62:1-135. 
R CORE DEVELOPMENT TEAM. 2008. R: A language and environment for statistical computing. $\mathrm{R}$ foundation for statistical computing, Vienna, Austria. ISBN 3-900051-07-0, URL http://www.R-project.Org.

READ, A. J., K. W. URIAN, B. WILSON, AND D. M. WAPLES. 2003. Abundance of bottlenose dolphins in the bays, sounds and estuaries of North Carolina, USA. Mar. Mammal Sci. 19:59-73.

TYSON, R. B., S. M. NOWACEK, AND D. P. NOWACEK. 2011. Community structure and abundance of bottlenose dolphins (Tursiops truncatus) in coastal waters of the Northeast Gulf of Mexico. Mar. Ecol. Prog. Ser. 438:253-265.

URIAN, K. W., A. A. HOHN, AND L. J. HANSEN. 1999. Status of the photo-identification catalog of coastal bottlenose dolphins of the western North Atlantic: report of a workshop of catalog contributors. NOAA Tech. Memo. NMFS-SEFSC-425.

WARING, G. T., E. JOSEPHSON, C. P. FAIRFIELD, AND K. MAZE-FOLEY. 2007. U.S. Atlantic and Gulf of Mexico marine mammal stock assessments - 2006. NOAA Tech. Memo., NMFS-NE-201, Woods Hole, MA. 453 p.

WARINGG. T., E. JOSEPHSON, K. MAZE-FOLEY, AND P. E. ROSEL, eds. 2011. U.S. Atlantic and Gulf of Mexico marine mammal stock assessments-2010. NOAA Tech. Memo. NMFS-NE-219, Woods Hole, MA. 598 p.

WELLS, R. S., AND M. D. SCOTT. 1999. Bottlenose dolphin Tursiops truncatus (Montagu, 1821). Pp. 137-182 in S. H. Ridgway and R. Harrison (eds.), Handbook of marine mammals, Vol. 6, The second book of dolphins and porpoises. Academic Press, San Diego, CA.

White, G. C., D. E. ANDERSON, K. P. BURNhAM, AND D. L. OTIS. 1982. Capture-recapture and removal methods for sampling closed populations. Rept. No. LA-8787-NERP. 14 p.

WILLIAMS, J., S. M. DAWSON, AND E. SLOOTEN. 1993. The abundance and distribution of bottlenosed dolphins (Tursiops truncatus) in Doubtful Sound, New Zealand. Can. Jo. of Zool. 71:2080-2088.

WILSON, B., P. S. HAMMOND, AND P. M. THOMPSON. 1999. Estimating size and assessing trends in a coastal bottlenose dolphin population. Ecol. Appl. 9:288-300.

\section{APPENDIX 1}

\section{Measurement of Photographic Quality and Dolphin Distinctiveness for Bottlenose Dolphin Photo-identification}

\section{OVERALL PHOTOGRAPHIC QUALITY}

Overall Photographic Quality is based on the quality of the photograph independent of the distinctiveness of the fin.

The Overall Photographic Quality score is based on an evaluation and sum of the following characteristics (these scores are absolute values, not a sliding scale):

\section{- Focus/Clarity}

Crispness or sharpness of the image. Lack of clarity may be caused by poor focus, excessive enlargement, poor developing or motion blur; for digital images, poor resolution resulting in large pixels.
Based on the scale: $2=$ excellent focus $4=$ moderate focus $9=$ poor focus, very blurry

\section{- Contrast}

Range of tones in the image. Images may display too much contrast or too little. Photographs with too much contrast lose detail as small features wash out to white. Images with too little contrast lose the fin into the background and features lack definition.

Based on the scale: $1=$ ideal contrast $3=$ either excessive contrast or minimal contrast

\section{- Angle}

Angle of the fin to the camera.

Based on the scale: $1=$ perpendicular to camera, $2=$ slight angle, $8=$ oblique angle

\section{- Partial}

A partial rating is given if so little of the fin is visible that the likelihood of re-identifying the dolphin is compromised on that basis alone. Fins obscured by waves, Xenobalanus, or other dolphins, would be evaluated using this rating.

Based on the scale: 1 = the fin is fully visible, leading and trailing edge, $8=$ the fin is partially obscured

\section{- Proportion of the frame filled by the fin}

An estimate of the percentage area the fin occupies relative to the total area of the frame.

Based on the scale: $1=$ greater than 5\%; subtle features are visible, $5=$ less than $1 \%$; fin is very distant

To score Overall Photographic Quality, sum the scores for each characteristic:

$$
\begin{aligned}
& \text { 6-9: Excellent quality } \geqslant Q \mathbf{Q}-1 \\
& \text { 10-12: Average quality } \geqslant Q-2 \\
& \text { >12: Poor quality } \geqslant \mathbf{Q - 3}
\end{aligned}
$$

\section{OVERALL DISTINCTIVENESS}

Overall Distinctiveness is based on the amount of information contained on the fin; information content is drawn from leading and trailing edge features, and pattern, marks, and scars.

D-1-Very distinctive; features evident even in distant or poor quality photograph

D-2 - Average amount of information content: 2 features or 1 major feature are visible on the fin

D-3-Not distinctive; very little information content in pattern, markings or leading and trailing edge features

These measurements are derived from:

Friday et al. 2000. Measurement of photographic quality and individual distinctiveness for the photographic identification of humpback whales, Megaptera novaeangliae. Marine Mammal Science 16: 355-374. 